Journal of Scientific Perspectives

Volume 3, Issue 3, Year 2019, pp. 223-228

E - ISSN: 2587-3008

URL: http://ratingacademy.com.tr/ojs/index.php/jsp

DOİ: https://doi.org/10.26900/jsp.3.023

Research Article

\title{
THE ROLE OF REGULARLY EXERCISE IN OVERCOMING INFERTILITY BARRIERS ${ }^{1}$
}

\author{
Yunus Emre TOPDAĞI * \& Şamil ÖZTÜRK * * \\ \& İlhan ÖZDEMİR *** \& Suat ÇAKINA ****
}

* Faculty of Medicine, Department of Gynecology and Obstetrics, Gaziantep Sanko University,

TURKEY, e-mail:emr_topdagi@hotmail.com

ORCID ID: https://orcid.org/0000-0003-0656-0765

** Health Services Vocational School, Canakkale Onsekiz Mart University, TURKEY, e-mail: samilozturk@hotmail.com

ORCID ID: https://orcid.org/0000-0002-9435-8139

*** Faculty of Medicine, Department of Gynecology and Obstetrics, Erzurum Ataturk University,

TURKEY, e-mail: ilhanozdemir25@yandex.com

ORCID ID: https://orcid.org/0000-0001-9957-0211

**** Health Services Vocational School, Canakkale Onsekiz Mart University, TURKEY,

e-mail: suatcakina@comu.edu.tr

ORCID ID: https://orcid.org/0000-0002-3990-7641

Received: 10 July 2018; Accepted: 19 July 2019

\begin{abstract}
Infertility is seen worldwide in developing countries and affects $30 \%$ of couples. Infertility causes depression, anxiety, social isolation, sexual dysfunction and decreased quality of life. In the treatment of infertility; besides medical treatment, significant advances have been obtained from the eastern medical strategies. Regular exercise programs, physical fitness are given to individuals. In addition, it makes them feel good about themselves physically and spiritually. It has been shown that exercise has a significant impact on health, and that regular exercise supports healthy body weight, good circulation, positive mental health, good digestion, a healthy body and helps reproduction. Complementary and alternative medicine, acupuncture and finally regular exercise are shown to be able to eliminate infertility problems. In this study, we aimed to explain the effects of exercise on male and female infertility and to create awareness.
\end{abstract}

Keywords: Infertility, Assisted reproductive techniques (IVF), Exercise 


\section{INTRODUCTION}

\subsection{Infertility}

Infertility is defined as being unable to conceive despite regular and unprotected sexual intercourse for one year. While pregnancy occurs in $80-85 \%$ of couples during this period and pregnancy cannot be achieved in 15\% (Duanif, 1992). In women, a decrease in fertility is observed depending on age, so if patients over 35 years of age do not develop pregnancy within 6 months, they are diagnosed with infertility and the treatment process begins. If the patient is older than 40 years and has a history of pelvic surgery, oligoamenorrhea, chemo-radiotherapy, male subfertility, and suspected utero-tubo-peritoneal disease, treatment should be started immediately without waiting for 6 months (ESHRE/ASRM, 2004). The number of infertile couples has increased due to stressful living conditions, unnatural nutrition and smoking habits. One in every 6-7 couples married today does not have children and has to seek medical help. However infertility can be caused by male and female reasons, pregnancy may not be obtained even though there is no significant problem in both cases. Examinations that should be included in the evaluation of basic infertility; Semen analysis determined according to WHO criteria,Tests that detect ovulation include evaluation of ovarian reserve by ultrasonographic antral follicle count and estrogen (E2) level measurement, clomiphene citrate test and hysterosalpingography (HSG) (The Practice Committee of the American Society for Reproductive Medicine, 2006). Infertility occurs in $40 \%$ of couples in men, $40 \%$ in women, $10 \%$ in men and women, and $10 \%$ in unknown causes. Therefore, both infertile couples should understand the problem and discuss it among themselves. Male infertility is due to many causes Sperm production disorders, blockages in sperm ducts, presence of antibodies to sperm, testicular trauma, hormonal disorders, anatomical problems, varicocele, past diseases, infections and certain drugs may cause infertility (Kumar, 2015). Regardless of the cause, infertility is not easy to overcome. Many infertile men feel incomplete and unhappy. Some people think have lost manhood. These feelings are normal and the way to overcome them is to communicate with other people. If we look at the cause of female infertility; endometriosis, polycystic ovary syndrome and unexplained infertility are the leading causes of infertility. Infertile couples should support each other to overcome these problems. It should be remembered that $90 \%$ of the causes of infertility can be treated and there are many treatment options.

The formation of highly reactive but unstable free radicals that are formed physiologically in the organism and their removal by antioxidant mechanisms are always in balance. Oxidative stress (OS) is the disruption of this balance in favor of free radicals (Aruoma, 1998). Stress is the body's response to various internal and external stimuli. Stress can cause physiological changes in the human body; In muscle system; tension, cramps, fatigue, also in the cardiovascular system; increases palpitation and blood pressure. This results in free radicals. Free radicals in physiological doses have important effects on ovulation, folliculogenesis, oocyte maturation, implantation and embryo development. If we look at the cause of female infertility; Endometriosis, polycystic ovary syndrome and unexplained infertility pathogenesis have been shown to be advanced free radical production. Therefore, there are studies proving that the addition of antioxidant agents to the culture media in patients who are planned for in vitro ertilization or oral or intravenous administration of antioxidant agents to patients in this group may increase fertility success and assisted reproductive techniques in patients. Many new techniques have been developed to minimize oocyte, sperm and embryo damage to increase pregnancy outcomes. The most commonly used ones are in vitro fertilization (IVF) and embryo transfer and intracytoplasmic sperm injection (ICSI) procedure. Oxidative stress is an important factor in the success of IVF. Oocyte and granulosa cells work in correlation with each other. Granulosa cells are useful for oocyte development-maturation, fertilization; they produce 
antioxidants to protect the oocyte from apoptosis, which is enhanced by oxidative stress. Oocytes develop around the follicular fluid. Follicular fluid affects oocyte quality, ability to interact with sperm, implantation and embryonic development of the embryo. In the absence of antioxidants in follicular fluid; Causes an increase in ROS (Reactive Oxygen Species) levels (Revelli, 2009, Jana, 2010).

\subsection{Exercise}

Physical activity is any body movement that is generated by skeletal muscles and leads to energy consumption (Kozanoğlu, 2007). Exercise, physical activity, produced as a result of contraction of skeletal muscles, which requires physical expenditure above the basal level of physical movements. Exercise is considered a subclass of physical activity. The aim of the exercise is to set the oxygen distribution and metabolic processes, improve strength, endurance, reduce body fat, and improve muscle and joint movements. However, exercise has a great effect on living systems. It should be done in a programmed way when exercising alone. When the effects of exercise are considered in terms of health, it is working muscles, keeping the heart's pumping ability in balance, regulating heart rate and blood pressure. For many animals, mobility is the foundation of life. For people, exercise; the meaning of life for a while means a way of life, sometimes entertainment, and sometimes treatment ( $\mathrm{Ji}, 1999)$. Being active and exercising have protective effects on all body functions and health. It is a well known fact that regular physical exercise reduces the risk of cardiovascular disease, cancer, osteoporosis and diabetes (Hara, 1997). Accompanying effects of complex mechanisms; reduction in adipose tissue; changes in lipid and hormone profile; adaptation of receptor and transport proteins; and changes in antioxidant defenseit has contains.

\subsection{Effect of Exercise on Infertility}

It has been proven that exercise has a significant impact on health, regular exercise provides a healthy body weight, good circulation, positive mental health, good digestion and support for a healthy body and helps reproduction ('Eliakim, 2010). Exercise has been shown to help weight control and contribute to the body with stress-hunting hormones (Eliakim, 2006). Proper diet and exercise are extremely important for optimal reproductive function. Physically fit men tend to have healthy sperm, but excessive exercise (especially in combination with the use of illegal bodybuilding steroids and other drugs) can reduce testosterone production and sperm count ( ${ }^{b}$ Elaikim, 2010). The male reproductive system consists of the hypothalamuspituitary unit and testes. The testes are responsible for the production of sperm and androgens, especially testosterone (Eliakim, 2009). Androgens are also responsible for the development of secondary masculinity, muscle and bone development, red blood cells, sex drive, and other behavioral aspects. The effect, severity and duration of physical activity on the male reproductive axis depends on the activity, fitness level of the individual and his nutritional status (La Gerche, 2008). In the experimental study on rats, intense exercise is practiced and known as athlete's nutrition the changes in testicular structure and serum testesterone levels were compared with the branched-chain amino acid (BCAA) amino acid supplementation. Sperm motility and serum testosterone levels were significantly increased in the exercise group after eight weeks of exercise and BCAA supplementation. In addition, sperm lipid peroxidation was decreased but there was no be seen difference between the groups in the seminiferous tubule diameters and meiotic index. It is estimated that amino acid supplementation can have a synergistic effect in endurance exercises, not intense exercise (Bahadorani, 2019).

Short and intensive aerobic and anaerobic exercise usually increases serum testosterone levels exercise serum testosterone reduction may rarely be associated with low libido and low sperm production (Milani, 2015). In addition, low testosterone levels have been reported to play an important role in many places such as decreased muscle development, decreased repair of 
muscle damage and weakened post-exercise muscle rehabilitation as it is associated with exercise. On the other hand, a decrease in low testosterone level has been found to have a negative effect on bone density mood and behavior. Surprisingly, changes in testosterone levels, their effects on performance and health are rarely evaluated in medically well-controlled elite athletes (Arce, 1993).

Clinical findings suggest that oxidant-antioxidant imbalance, which is the underlying cause of many diseases, also plays an important role in male infertility. 24-week resistance exercise and the seminal plasma oxidative stress status, inflammatory markers and DNA integrity were evaluated in the study conducted in 1228 patients in the analysis of oxidative stress and inflammatory markers were found to reduce the oxidative stress and increased reproductive performance (Hajizadeh, 2018).

Regular exercise in women leads to a more regular menstrual cycle and may increase the frequency of ovulation. As ovulation becomes more frequent, the chances of becoming pregnant increase. Polycystic ovary syndrome (PCOS) is a complex condition associated with infertility. In women with PCOS, the menstrual cycle is irregular and oocyte excretion by ovulation is rare. Regular exercise for PCOS and overweight women can increase ovulation temperature, which leads to a more regular menstrual cycle. As ovulation becomes more frequent, the chances of becoming pregnant increase. While studies have shown that exercise increases female fertility, it is important to note that many high-intensity exercises can reduce fertility and the chance of having a baby with IVF. Therefore, it is a good idea to avoid doing very high intensity exercise while you are requesting a baby (ESHRE/ASRM, 2003).

Regular exercise programs, as well as individuals to gain physical fitness it also makes him feel good physically and spiritually. Exercise increases ovarian function and chances of conception by increasing insulin sensitivity (Lewis, 1997). After adjustments to body mass index, intensive exercise program by $5 \%$ every week can reduce the risk of ovulatory infertility.

This shows that there is evidence that physical activity can protect ovarian functions independent of body mass index (Lehmann, 1997). In a study conducted with obese and infertile women; weight loss, improvement of physical fitness and psychological well-being increased ovulation and pregnancy rates. It is thought that moderate exercise and a well-adjusted diet will positively affect fertility as well as overall health benefits (Meeker, 2007). Studies have shown that exercise reduces blood sugar, adds elasticity and strength to muscles, reduces stress, and it is stated that exercise should be started before becoming pregnant (Chavarro, 2008). Scientific studies have shown that exercise increases the chance of pregnancy by increasing insulin sensitivity and regulating ovarian function. In a study conducted in the USA, it was found that women who exercise more than 4 hours a week had more negative IVF results in in vitro fertilized patients, and it was suggested that exercise should not exceed 4 hours a week in couples with infertility problems. In order to increase the chances of pregnancy in infertility, a moderate 30 minute exercise 5 days a week is sufficient for adults (Frisch, 2002). As a result exercise to moderate weight strengthens antioxidant defense mechanisms in both circulation and tissues. Thus, oxidative stress factors that affect gamet cells in the reproductive organs are removed and cell damage is prevented. As a result, in order to overcome infertility problems, exercise should be an integral part of our lives.

\section{RESULTS}

As a result, overweight in both men and women can directly affect oocyte and sperm quality and reduce fertility. Regular moderate exercise can help women and men to lose weight or stay in a healthy weight range, thereby improving sperm quality in men and regulating ovulation in women, ensuring good quality oocyte excretion. In addition, the rate of couples treated with assisted reproductive techniques such as IVF can increase considerably. However, 
it is recommended that couples avoid long-term and high-intensity exercises, especially during periods of intention to have children and during IVF treatment. Consequently; exercise is supported by clinical and experimental studies that provide a healthy mental and physical health as well as an alternative solution for having children in infertile individuals who cannot have children.

\section{REFERENCE}

ARCE, J.C., De SOUZA, M.J., PESCATELlO, L.S., LUCIANO, A.A., 1993. Subclinical alterations in hormone and semen profile in athletes. Fertil Steril, 59(2): 398-404.

ARUOMA, O.I., 1998. Free radicals, oxidative stress, and antioxidants in human health and disease. Journal of the American Oil Chemists' Society JAOCS, 75,199-212.

BAHADORANI, M., TAVALAEE, M., NAVID, ABEDPOOR, N., GHAEDI, K., NAZEM, M.N., NASR-ESFAHANI, M.H., 2019. Effects of branched-chain amino acid supplementation and/or aerobic exercise on mouse sperm quality and testosterone production. Andrologia, 51(2):e13183. doi: 10.1111/and.13183.

CHAVARRO, J.E., WILLETT, W.C., SKERRETT, P.J., 2008 The fertility diet. New York, NY: The McGraw Hill Companies, Inc.

DUANIF, A, GIVENS, J.R., HASELTINE, F.P., MERRIAM, G.R., 1992, Blackwell Scientific Publications, Boston.

ELIAKIM, A., NEMET, D., 2006. Exercise and the male reproductive system. Harefuah 145, 677-81.

ELIAKIM, A., PORTAL, S., ZADIK, Z., RABINOWITZ, J., ADLER-PORTAL, D., COOPER. D.M., ZALDIVAR, F., NEMET, D., 2009. The effect of a volleyball practice on anabolic hormones and inflammatory markers in elite male and female adolescent players. J Strength Cond Res, 23(5):1553-9.

${ }^{a}$ ELIAKIM, A., NEMET, D., 2010. Endogenous hyperandrogenism and exercise capacity lessons from the exercise-congenital adrenal hyperplasia model. J Pediart Endokrinol Matab, 23(12), 1213-9.

${ }^{\mathrm{b}}$ ELIAKIM, A., NEMET, D., 2010. Exercise training, physical fitness and the growth hormoneinsulin-like growth factor-1 axis and cytokine balance. Med Sport Sci, 55:128-40. doi: $10.1159 / 000321977$.

FRISCH, R.E., 2002. Female fertility and the body fat connection. Chicago: University of Chicago Press.

HAJIZADEH, MALEKI B., TARTIBIAN, B., 2018. Resistance exercise modulates male factor infertility through antiinflammatory and antioxidative mechanisms in infertile men: A RCT Life Sci,203:150-160. doi: 10.1016/j.1fs.2018.04.039.

HARA, M., IIGO, M., OHTANI-KANEKO, R., NAKAMURA, N., SUZUKI, T., REITER. R.J., HIRATA, K., 1997. Administration of melatonin and related indoles prevents exercise- induced cellular oxidative changes in rats. Biol Signals, 6:90-100. DOI:10.1159/000109113. 
JANA, S.K., K N.B., CHATTOPADHYAY, R., CHAKRAVARTY, B., CHAUDHURY, K., 2010. Upper control limit of reactive oxygen species in follicular fluid beyond which viable embryo formation is not favorable. Reprod Toxicol, 29(4), 447-451.

JI, L.L., 1999. Antioxidants and oxidative stress in exercise, Proc Soc Exp Biol Med, 222(3), 283-292.

KOZANOĞLU, M.E., 2007. Adölesan ve egzersiz. Çukurova Ünv. Tıp Fakültesi Fiziksel Tıp ve Rehabilitasyon Anabilim Dalı Ders Notları.

KUMAR, N., \& SINGH, A. K., 2015. Trends of male factor infertility, an important cause of infertility: A review of literature. Journal of human reproductive sciences, 8(4), 191196. doi:10.4103/0974-1208.170370.

La GERCHE, A., CONNELLY, K.A., MOoney, D.J., MACISAAC, A.I., PRIOR, D.L., 2008. Biochemical and functional abnormalities of left and right ventricular function after ultra-endurance exercise. Heart, 94(7): 860-6.

LEHMANN, M.J., LORMES, W., OPITZ-GRESS, A., et al., 1997. Training and overtraining: an overview and experimental results in endurance spor. J Sports Med Phys Fitness,37(1):7-17.

LEWIS, S.E., STERLING, E.S., YOUNG, I.S., THOMPSON, W., 1997. Comparison of individual antioxidants of sperm and seminal plasma in fertile and infertile men. Fertil Steril, 67(1): 142-7.

MEEKER, J.D., GODFREY-BAILEY, L., HAUSER, R., 2007. Relationships between serum hormone levels and semen quality among men from an infertility clinic. J Androl, 28(3): 397-406.

MILANI, R.V., LAVIE, C.J., MEHRA, M.R., VENTURA, H.O., 2011. Impact of Exercise Training and depression on survival in heart failure due to coronary heart disease. Am J Cardiol, 107(1): 64-8.

REVElli, A., DELle PIANE, L., CASANO, S., MOLINARI, E., MASSOBRIO, M., \& RINAUDO, P., 2009. Follicular fluid content and oocyte quality: from single biochemical markers to metabolomics. Reproductive biology and endocrinology: $R B \& E, 7$, 40. doi:10.1186/1477-7827-7-40.

Rotterdam ESHRE/ASRM-Sponsored PCOS Consensus Workshop Group, 2004. Revised 2003 consensus on diagnostic criteria and long-term health risks related to polycystic ovary syndrome (PCOS). Human Reproduction, 19(1),41-47.

The Practice Committee of the American Society for Reproductive Medicine, 2006. Optimal evaluation of the infertile female. Fertil Steril. 86,264-7. 